\title{
BLOCKCHAIN: A REGULAÇÃO ECONÔMICA DAS CRIPTOMOEDAS E SUA EFETIVIDADE
}

\section{BLOCKCHAIN: ECONOMIC REGULATION OF CRIPTOCURRENCY AND ITS EFFECTIVENES}

\author{
Lorena de Melo Freitas ${ }^{1}$ \\ Sandro Mansur Gibran ${ }^{2}$ \\ Guilherme Ramos Justus ${ }^{3}$
}

\begin{abstract}
Resumo
A tecnologia digital contribui significativamente para o desenvolvimento de uma economia global e cada vez mais compartilhada entre seus usuários. Assim, para se seja possível realizar transações de forma rápida e sem intermediários, o uso de criptomoedas tem crescido consideravelmente, pois esta surgiu como uma alternativa segura para movimentar a economia mundial de forma independente. Obviamente, o crescente uso da tecnologia faz com que seja necessária uma mudança estrutural e
\end{abstract}

1Professora dedicação exclusiva da UFPB (Associada I), ensinando na Graduação (Hermenêutica Jurídica, Direito Internacional Privado) e Pós-Graduação em Direito - Mestrado e Doutorado (Metodologia, Teoria Geral do Direito). Membro do GT Ética e Cidadania da ANPOF. Graduada (UNICAP), Mestra e Doutora (UFPE) em Direito. Desenvolve pesquisas voltadas à atividade judicial desde o mestrado quando defendeu Dissertação intitulada ?Ideologia e direito: uma pesquisa empírica sobre a Associação Juízes para a Democracia? e no Doutorado com tese sobre a formação da decisão por juízes e tribunais sob título ?O realismo jurídico como pragmatismo: A retórica da tese realista de que direito é o que os juízes dizem que é direito?. Tem livros publicados e organizou obras coletivas sobre estas temáticas, tendo, para realização de suas atividades fundado o Grupo de Pesquisa ligado ao PPGCJ/UFPB: ?Realismo Jurídico?. Participa como pesquisadora de outros grupos de pesquisa ("Marxismo e Direito", "Pragmatismo Jurídico, Teorias da Justiça e Direitos Humanos" e "Fundamentos e Métodos do Pragmatismo: uma abordagem interdisciplinar dos fenômenos jurídicos") e tem como foco de pesquisa os seguintes temas: Realismo jurídico, ideologia, retórica, teoria geral, filosofia e sociologia do direito. A pesquisa de Pós-doutorado se intitulou: Espaços jurídicos emancipadores e inclusão como direito ao desenvolvimento sociopolítico: Uma crítica anisiana acerca das interfaces da pós-graduação com a educação básica em atenção à meta de 2007/2008 da CAPES.

${ }^{2}$ Graduado em Direito pela Faculdade de Direito de Curitiba (1996), Mestre em Direito Social e Econômico pela Pontifícia Universidade Católica do Paraná (2003) e é Doutor em Direito Econômico e Socioambiental pela Pontifícia Universidade Católica do Paraná (2009). Atualmente é professor do Programa de Mestrado em Direito do Centro Universitário Curitiba - UniCuritiba, também de Direito Empresarial e de Direito do Consumidor da Faculdade de Direito do Centro Universitário Curitiba UniCuritiba -, de Direito Empresarial junto ao Centro de Estudos Jurídicos do Paraná e junto à Escola da Magistratura Federal do Paraná, além de coordenador do Curso de Pós-Graduação em Direito Empresarial do Centro Universitário Curitiba - UniCuritiba - e advogado desde 1997, atuante na área de Direito Empresarial.

${ }^{3}$ Pós-doutorado na Faculdade de Direito do Largo São Francisco (USP). Doutor em Direito Tributário pela Pontifícia Universidade Católica de São Paulo (2012). Mestre em Direito Econômico e Social (2004) e Especialista em Direito Empresarial (2000), ambos pela Pontifícia Universidade Católica do Paraná, Bacharel em Direito pela Universidade Federal do Paraná (1994). Professor de Direito Tributário na graduação, especialização, mestrado e doutorado na Faculdade de Direito Curitiba (UNICURITIBA), Professor Convidado no Curso de Posgrado en Derecho Tributario na Universidad Austral de Buenos Aires/Argentina e Ex-professor da Faculdade Autônoma de Direito de São Paulo (2006-2007) e na graduação e especializaçao da Pontifícia Universidade Católica do Paraná (2000-2006/2011-2013).

${ }^{3}$ Guilherme Ramos Justus. Advogado. Bacharel em Direito pelo Centro Universitário Curitiba (2013) Especialista em Direito Penal e Processual Penal pelo Centro de Estudos Prof. Luiz Carlos - OPET (2014), Especialista em Direito Aplicado pela Escola da Magistratura do Paraná (2015), Mestrando em Direito Empresarial e Cidadania pelo Centro Universitário Curitiba. 
jurídica pelo Estado. Diante de tal contexto, busca-se compreender de que forma deverá o Estado agir, e eventualmente regular o seu uso, ciente de que as mudanças estruturais são inevitáveis, mas sem limitar o alcance pretendido pelos desenvolvedores das criptomoedas.

Palavras-chave: criptomoedas, blockchain, regulação estatal.

\begin{abstract}
Digital technology contributes significantly to the development of a global economy increasing sharing among its users. Thus, to be able to perform transactions quickly and without intermediaries, the use of cryptocurrencies has grown considerably, as it has emerged as a safe alternative to move the world's economy independently. Obviously, the increasing use of technology needs a structural and legal change by the state. In this context, we seek to understand how the state should act, and eventually regulate its use, aware that structural changes are inevitable, but without limiting the scope intended by cryptocurrency developers.
\end{abstract}

Keywords: cryptocurrency, blockchain, state regulation.

\title{
1. INTRODUÇÃO
}

Não é novidade que o mundo globalizado influencia frontalmente todas as relações humanas, sejam elas sociais ou econômicas. A obra de Klaus Schwab sobre a quarta revolução industrial deixa claro que as mudanças que o mundo digital proporciona não possuem precedentes (SCHWAB, 2016). Em uma visão mais voltada ao pensamento sociológico, pode-se dizer que a contemporaneidade é uma consagração da obra "Modernidade Líquida" de Zygmunt Baumann (2003).

O desenvolvimento de uma economia globalizada e compartilhada, a evolução não linear de certas economias, bem como a demanda por transações com maior dinamicidade fazem parte do atual cenário, o qual mostrou-se como o ambiente perfeito para o surgimento de tecnologias que tornam ultrapassas as tradicionais formas de relacionamento sociopolítico. Assim, as novas tecnologias demandam reflexão sobre como o ordenamento jurídico pode se adaptar à nova realidade digital.

Uma das mais impactantes tecnologias é a criação das criptomoedas, as quais possibilitam a realização de transações econômicas através de um meio de pagamento desvinculado a um Estado soberano, de uma moeda física, bem como de um terceiro que possa regular o fluxo de transações. Apesar de ser uma modalidade que ainda cause 
muitas ressalvas por agentes econômicos mais tradicionalistas, a segurança, segundo seus desenvolvedores, é garantida tanto por um sistema criptografado quanto por seus próprios usuários, os quais têm acesso ao registro de todas as transações realizadas dentro da carteira de investimentos. Ou seja, em termos objetivos, criou-se um meio de realizar transações econômicas que, em tese, reduz drasticamente o grau de intervenção do Estado na economia. Mais, com sua maior disseminação, em tese cada vez mais global, a produção de uma moeda física e nacional perde relevância. Como consequência natural desses vetores há uma considerável diminuição do poder estatal pela redução de poder econômico.

Desta forma, considerando-se que os efeitos da quarta revolução industrial não podem ser deixados de lado, bem como o fato de que a economia globalizada e praticamente livre de fronteiras geográficas já é uma realidade, cabe aos Estados soberanos repensar de que forma passarão a tratar questões relativas ao monopólio da moeda tradicional, bem como de que forma passarão a tratar as criptomoedas dentro de seus ordenamentos.

Assim, o objetivo do presente artigo é analisar os principais aspectos das criptomoedas e sua respectiva influência em uma economia globalizada e digital, bem como verificar a possibilidade de uma regulamentação para o seu uso, mas obedecendo os ideais defendidos pelos seus desenvolvedores.

\section{A QUARTA REVOLUÇÃO INDUSTRIAL E SEUS PRINCIPAIS EFEITOS NA ECONOMIA}

Ainda que pareça abstrato, a ideia de a contemporaneidade já vive em uma quarta revolução industrial é primordial para o aprofundamento do tema proposto. Klaus Schwab (2016) entente que presenciando o início de uma revolução que alterará profundamente a maneira como vivemos, trabalhamos e nos relacionamos, pois terá uma escala e complexidade muito diferente do que já foi experimentado pela sociedade. Para tanto, o fundador do Fórum Econômico Mundial justifica três razões que sustentam a ideia de que já superamos a terceira revolução industrial, são elas: a velocidade exponencial e não linear da tecnologia; a amplitude e profundidade em que as novas tecnologias chegam aos seus usuários; bem como o impacto sistêmico que as mudanças sociais econômicas causarão nas empresas, indústrias e nas estruturas 
políticas (SCHWAB, 2016, p. 13). De forma objetiva, o que diferencia a quarta revolução industrial das suas anteriores é o fato de que a atual se utiliza da fusão das tecnologias com os domínios físicos, digitais e biológicos. Ainda, Schwab defende que a quarta revolução industrial será tão (ou mais) poderosa que as lhe precederam ${ }^{4}$.

Considerando tal prognóstico, a evolução tecnológica influenciará radicalmente as relações comerciais, principalmente pelo fato de que o amplo acesso à internet fomenta transações cada vez mais dinâmicas. Tal dinamismo, por sua vez, fez com que multiplicassem a oferta de serviços por demanda pessoal e um aumento de relação de confiança, uma vez que todas as relações são travadas em um meio público e digital. Desta forma, desenvolveram-se tecnologias que propiciam um ambiente de confiança para que sejam registradas as transações feitas através do ambiente digital, sendo as duas principais delas o Blockchain e as criptomoedas.

Desta forma, em primeiro plano, para que seja viável estabelecer uma discussão a respeito do grau de regulação tecnológica e seus reflexos econômicos, mostra-se fundamental que alguns conceitos provenientes da quarta revolução industrial sejam abordados para que seja possível compreender a necessária reestruturação de pensamento quanto ao grau de regulação da tecnologia e seus reflexos econômicos.

Partindo-se da ideia de que vivemos em uma sociedade globalizada e digital, a noção de uma economia compartilhada é fundamental. Como simples exemplo de economia compartilhada, pode-se referenciar empresas de exponencial crescimento mundial, como Uber, Facebook, Alibaba e Airbnb ${ }^{5}$, as quais também são classificadas como exemplos de economias sob demanda. A principal mudança de orientação econômica, bem como a principal razão de grande penetração no mercado, é o fato de que a tecnologia permite que se registrem transações de forma segura, o que torna viável o uso compartilhado de bens. Em síntese, relativiza-se a noção que o poder econômico

\footnotetext{
4 "A segunda revolução industrial precisa ainda ser plenamente vivida por $17 \%$ da população mundial, pois quase 1,3 bilhão de pessoas ainda não têm acesso à eletricidade. Isso também é válido para a terceira revolução industrial, já que mais da metade da população mundial, 4 bilhões de pessoas, vive em países em desenvolvimento sem acesso à internet. $\mathrm{O}$ tear mecanizado (a marca da primeira revolução industrial) levou quase 120 anos para se espalhar fora da Europa. Em contraste, a internet espalhou-se pelo globo em menos de uma década." (SCHWAB, 2016, p. 17)

${ }^{5} \mathrm{~A}$ economia sob demanda gera uma questão fundamental: $\mathrm{O}$ que vale a pena possuir - a plataforma ou o ativo subjacente? Em março de 2015, o estrategista de mídia Tom Goodwin escreveu em um artigo para o TechCrunch: O Uber, a maior empresa de táxis do mundo, não possui sequer um veículo. $\mathrm{O}$ Facebook, o proprietário de mídia mais popular do mundo, não cria nenhum conteúdo. Alibaba, o varejista mais valioso, não possui estoques. E o Airbnb, o maior provedor de hospedagem do mundo, não possui sequer um imóvel. (SCHWAB, 2016, p. 28)
} 
está na propriedade de bens. Passa-se a questionar se possuir o bem é, de feto, estritamente necessário.

Segundo tal tendência, a atual revolução digital criou abordagens radicalmente novas que propiciam maiores colaborações de indivíduos nas relações comerciais. A tecnologia Blockchain propicia que qualquer usuário tenha a capacidade computacional para se conectar e validar transações, sejam elas econômicas ou não. De forma bastante objetiva, Blockchain, ou em uma tradução literal "corrente de blocos", é uma cadeia funciona como uma espécie de livro-contábil, pois é uma ferramenta de compartilhamento entre usuários, de forma programável, criptograficamente seguro e, em tese, confiável. Ela não é fiscalizada ou controlada por um único usuário, ou por um ente superior, mas é inspecionado por todos os membros da cadeia de elos (SCHWAB, 2016, p.27). Desta forma, as transações financeiras realizadas nessa plataforma são publicadas e assinadas digitalmente pelo usuário emissor do pagamento mediante a aposição da chave correspondente à sua carteira digital. Essa assinatura garante a autenticidade e a validade da transação realizada perante todos os usuários da rede. Os elos dessa corrente que atuam como "mineradores" validam se há saldo na carteira do pagador e organizam as transações em blocos de dados a serem registrados na rede. Desta feita, cada partícula de dados é iniciada por uma chave criptografada do bloco que lhe antecedeu, resultando em um registro sequencial de transações que não podem ser alteradas, nem canceladas. Em outras palavras, cada transação registrada e efetivada criará um elo (ou um bloco) novo na corrente, o que justifica a utilização do termo Blockchain (STELLA, 2016, p. 152-153).

Destaque-se que a Blockchain não se resume exclusivamente às transações financeiras. Klaus Schwab defende que em um futuro muito próximo (na próxima década) este sistema servirá para registrar e validar nascimentos, óbitos, títulos de propriedade, certidões de casamento, diplomas escolares, pedidos às seguradoras, procedimentos médicos e até votos (SCHWAB, 2016, p. 28). Desta forma esse livrocontábil digital ganha notoriedade e mostra-se como um preceito fundamental para que se desenvolva a ideia da moeda virtual ou criptomoeda.

Neste ponto, novamente há a necessidade de novas pontuações conceituais, uma vez que as moedas digitais reclamam novas classificações e interpretações no tocante à sua natureza jurídica. Quando se aborda o tema das criptomoedas, a associação ao Bitcoin é quase que instantânea, pois é a expoente no mercado digital. Criado por Satochi Nakamoto, o qual acredita-se tratar-se de um pseudônimo, o Bitcoin surgiu em 
2009 para servir como uma alternativa econômica frente à grande crise mundial de $2008^{6}$. Ainda que se utilizem termos técnicos de necessário aprofundamento, o próprio site do bitcoin apresenta uma definição do que vem a ser essa criptomoeda. Segundo seu criador, ela seria uma rede operada de forma consensual onde criada uma forma de pagamento através de uma nova moeda digital. É uma rede de pagamento descentralizada onde os próprios usuários gerenciam o sistema, sem necessidade de intermediador ou autoridade central estatal (BITCOIN, 2019).

Por se tratar de um tema relativamente novo no âmbito jurídico, poucos pesquisadores do ramo do direito se aventuraram na elaboração de um conceito, porém, destaca-se a contribuição de Júlio Cesar Stella (2017), o qual define que criptomoeda é um ativo digital denominado na sua própria unidade de conta o qual é emitido e transacionado de modo descentralizado, independentemente de registro ou validação por parte de intermediários, com validade e integridade de dados assegurada por criptografia e por consenso em rede (STELLA, 2017. p. 151). Compreende-se a dificuldade da conceituação uma vez que se trata de um meio de viabilização de transferências de valores de forma independente de um sistema financeiro interventor, no caso, um Estado soberano ou um banco.

Para se seja possível a circulação de qualquer criptomoeda, é fundamental que seja realizado o processo de "mineração". Curiosamente, utiliza-se a expressão análoga à prática de extração de metais preciosos para a confecção de moedas, mesmo que não exista um respaldo físico nesse processo. Esse procedimento consiste em um grande processamento de dados através de criptografia ${ }^{7}$, sendo realizada por particulares que apresentam a prova de trabalho (proof of work), pela qual são remunerados em razão

\footnotetext{
6 “A primeira especificação do Bitcoin e prova de conceito foi publicado em 2009 em uma lista de criptografia por Satoshi Nakamoto. Satoshi deixou o projeto no final de 2010, sem revelar muito sobre si mesmo. A comunidade desde então tem crescido exponencialmente com muitos desenvolvedores_trabalhando em Bitcoin. $\mathrm{O}$ anonimato de Satoshi frequentemente levantou preocupações injustificadas, muitos dos quais estão ligados a incompreensão da natureza open-source de Bitcoin. O protocolo e software Bitcoin são publicados abertamente e qualquer desenvolvedor em todo o mundo pode rever o código ou fazer a sua própria versão modificada do software Bitcoin. Assim como os desenvolvedores atuais, a influência de Satoshi limitou-se às mudanças que ele fez sendo adotada por outros e, portanto, ele não controlou Bitcoin. Como tal, a identidade do inventor do Bitcoin é provavelmente tão relevante hoje quanto a identidade da pessoa que inventou o papel." Disponível em $<$ https://bitcoin.org/pt_BR/faq> Acesso em 14 out. 2019.

7 "Mineração é o processo de usar capacidade de processamento para processar transações, garantir a segurança da rede, e manter todos participantes do sistema sincronizados. Pode ser considerado como o datacenter do Bitcoin exceto que foi projetado para ser totalmente descentralizado, com mineradores em todos os países e nenhum em particular tendo controle sobre a rede" Disponível em <https://bitcoin.org/pt_BR/faq > Acesso em 14 out. 2019.
} 
do processo de mineração. Novamente, cabe o destaque de que não há uma intervenção de bancos (particulares ou estatais) ou de Estados soberanos.

Uma outra característica fundamental para que seja possível compreender a praticidade e agilidade da criptomoeda diz respeito ao seu sistema de transmissão, o qual é chamado de ponto-a-ponto ${ }^{8}$ (peer-to-peer ou P2P, na linguagem própria do sistema digital). Esse sistema funciona como uma organização coletiva de dados, o qual permite que cada usuário transacione diretamente como outro usuário, sem intermediários, o que reafirma a ideia central de ser uma moeda alternativa ao sistema financeiro atual, pois tradicionalmente seria necessário que ambos tivessem uma vinculação à um banco, o qual cobra taxas pela transferência de valores, e a uma moeda física vinculada ao Estado.

Com tais noções preliminares sobre criptomoedas, cabe a ponderação de que há uma diferenciação no sentido de que seus valores escriturais são denominados na própria unidade de conta, possuem estrutura de operação descentralizada, com governança definida no software pelo qual é operada. Tais pontos são relevantes uma vez que apesar de utilizarmos a nomenclatura "criptomoeda", a expressão engloba dois conceitos independentes, sendo "cripto" como referência da proteção feita através de criptografia e "moeda" por ser a forma mais usual de pagamento.

Ocorre que apesar usar tal nomenclatura, as criptomoedas não compartilham uma vasta identidade conceitual, principalmente no campo jurídico, uma vez que a natureza jurídica resta nebulosa em razão das características apontadas nos parágrafos anteriores. Atualmente, a classificação jurídica mais abrangente e usual é de que as criptomoedas são um bem incorpóreo, sendo um domínio eletrônico com valor abstrato ao qual se atribui direito de propriedade (STELLA, 2017 p. 161).

Consequentemente, apesar de não ter status jurídico de moeda clássica, as criptomoedas possuem relevantes propriedades econômicas. Nesse sentido, levando-se em conta as pontuações feitas por Lopes e Rosseti ${ }^{9}$, pode-se equiparar alguns atributos comuns, sendo eles: material como meio de troca; medida de valor; unidade de conta; unidade de reserva de valor; instrumento liberatório de obrigações; padrão de

\footnotetext{
8 "Ponto-a-ponto refere-se aos sistemas que trabalham como uma organização coletiva, permitindo que cada indivíduo interaja diretamente com outros. No caso do Bitcoin, a rede é construída de modo que cada utilizador transmite as transações de outros. E, fundamentalmente, bancos não são necessários para intermediar as transações" Disponível em $<$ https://bitcoin.org/pt BR/faq > Acesso em 14 out. 2019.

${ }^{9}$ LOPES, J.C. \& ROSSETTI, J.P. Economia Monetária. 9.ed. São Paulo: Editora Atlas, 2009.
} 
pagamentos diferidos; e, por fim, um instrumento de $\operatorname{poder}^{10}$, o qual passa a ser um ponto chave no tocante à possibilidade de regulação desse mercado digital. Ademais, o fato de ser um instrumento de poder, relaciona-se diretamente com o grau de intervenção estatal na economia, o que, em tese, vai de encontro com o ideal pretendido pelo criador das criptomoedas.

Desta forma, a utilização de um ambiente digital para realização de transações independente do poder estatal renova a discussão a respeito do grau intervenção do Estado na economia. Diante desse panorama, o direito financeiro e, consequentemente, o direito administrativo passam a enfrentar discussões profundas a respeito da necessidade de repensar a forma de fiscalizar e regular movimentações financeiras através da internet.

\section{BREVES APONTAMENTOS LEGAIS SOBRE AS CRIPTOMOEDAS}

Muito embora a conceituação apresentada até o momento destaque uma série de vantagens e atenda quase que integralmente os anseios de uma economia compartilhada contemporânea, não se pode atestar que o sistema da Blockchain e a utilização das criptomoedas está imune a fraudes e invasões de privacidade. Nesse sentido, deve-se sempre ressaltar que não há um sistema cem por cento seguro, mesmo que se utilize a criptografia. Qualquer sistema de informação que utiliza a internet está sujeito aos ataques de hackers e crackers, ou seja, a vulnerabilidade é exatamente a mesma dos sistemas de internet banking, já tidos como tradicionais meios transferência de valores.

A questão de segurança no universo do comércio digital ganhou fôlego em razão do midiático caso Silkroad ${ }^{11}$, onde um jovem americano desenvolveu, com a ajuda de um software que lhe conferia um considerável anonimato, uma rede de compra

\footnotetext{
10 “'Outro aspecto econômico que merece destaque é o lado político-econômico da atribuição de valor a uma moeda. As moedas estatais de curso forçado contam não apenas com reservas legais, mas também com uma infraestrutura estatal ou privada (fortemente regulada) e com as políticas monetária e cambial oficiais." (STELLA, 2017, p. 156).

11 "Ross Ulbrich, norte-americano nascido em 1984, assumindo o codinome de Dread Pirate Roberts (extraído do romance The Princess Bridge), ganhou importante papel no mundo virgual, sendo tido como o criador da chamada Solk Road. Esta nada mais era do que um mercado negro visto genericamente da deepweb, por onde seria possível o comércio de mercadorias ilícitas." SILVEIRA. Renato de Mello Jorge; Bitcoin e suas fronteiras penais: em busca do marco penal das criptomoedas. Belo Horizonte: D’Placido, 2018. P. 133.
} 
e venda de substâncias ilícitas através de criptomoedas. Porém, fundamental é noção de que a utilização de criptomoedas não é um ilícito em si. Nesse caso, a torpeza é a mesma de qualquer outro tipo penal patrimonial, o que difere é exclusivamente o meio em que é realizado, no caso, o digital.

Ademais, relembre-se que apesar de compartilharem atribuições e características de moeda tradicional, utilizar criptomoedas não poderia ser objeto de crime de moeda falsa (art. 289, do Código Penal ${ }^{12}$ ), uma vez que seu conceito não se amolda ao tipo penal em questão. O ponto de maior debate no âmbito criminal diz respeito ao combate à lavagem de capitais, uma vez que o sistema de pseudoanonimato e a facilidade de transações internacionais contribui consideravelmente com a ocultação e a posterior recolocação do dinheiro no mercado ${ }^{13}$.

\section{PERSPECTIVAS DO DIREITO ADMINISTRATIVO E A EVENTUAL REGULAÇÃO PELO ESTADO.}

Diante de tal cenário, é inevitável a constatação de que os impactos desta revolução industrial provocam questionamentos se é possível, bem como desejável que a tecnologia se converta no principal regulador de comportamentos da sociedade. Ademais, os questionamentos sobre regulação tocam temas sensíveis politicamente, como a soberania de um Estado, bem como a democracia.

É claro que em um contexto de mundo globalizado, o direito considerado “doméstico" passa não ser mais o foco das principais discussões sociopolíticas, uma vez que o mundo digital supera os limites territoriais estabelecidos pela geografia. Uma

\footnotetext{
${ }^{12}$ Art. 289 - Falsificar, fabricando-a ou alterando-a, moeda metálica ou papel-moeda de curso legal no país ou no estrangeiro: Pena - reclusão, de três a doze anos, e multa.

13 "A lavagem de capitais com criptomoedas, como a BTC, é possível. O poder de incrementar o risco de lavagem que é derivado de suas três características principais (a descentralização, a "pseudoanonimidade" e a globalidade) poderá, porém, ser bastante mitigado quando as exchanges estiverem sujeitas às medidas de prevenção e controle de lavagem. Isso porque a identificação dos usuários, que será por elas realizada, somada à total transparência das transações no blockchain tornarão a rastreabilidade bastante superior àquela que se tem hoje, por exemplo, relativamente ao dinheiro em espécie. Restam, porém, os desafios postos pela descentralização e, especialmente, pela globalização, que permitem a movimentação dos valores de forma extremamente rápida ao redor do mundo. Estes desafios indicam a necessidade de uma intensa e eficaz cooperação internacional em matéria financeira e penal." ESTELLITA, Heloisa. Bitcoin e lavagem de dinheiro: uma aproximação. Penal em foco. Portal Jota. Disponível em < https://www.jota.info/paywall?redirect to=//www.jota.info/opiniao-eanalise/colunas/penal-em- foco/bitcoin-e-lavagem-de-dinheiro-uma-aproximacao-07102019> Acesso em 12 nov. 19.
} 
simples constatação pode ser observada através da internacionalização dos direitos humanos, aliado às integrações regionalizadas entre grupos de países, como ocorre no Mercosul e na União Europeia. Objetivamente, são produtos do fenômeno da globalização. Desta forma, como uma consequência natural, a noção de um direito global acaba por enfraquecer noções e particularidades nacionais, políticas e sociais (SUNDFELD, 2014, p. 286). De forma muito didática, Carlos Ari Sundfeld, ao abordar os desafios do direito administrativo na sociedade globalizada, aponta que o direito global influencia frontalmente o direito pátrio no sentido de que cria variadas cadeias de normas, sejam decorrentes do mercado jurídico interno, seja por influência internacional; uma complexa estrutura de órgãos estatais e internacionais que alternam entre produção e aplicação do direito; por fim, a internacionalização da economia, a qual possui interesses especiais (2014, p. 287).

Diante de tais influências externas, os questionamentos sobre soberania e direito administrativo são inevitáveis. Inclusive, Sundfeld questiona se o direito administrativo, da forma como o se conhece atualmente, será extinto. Felizmente, Sundfeld conclui que o que caracteriza o direito administrativo é a submissão da Administração ao Direito e não necessariamente à lei em seu sentido estrito, proveniente do Poder Legislativo (p. 290). Em outras palavras, a soberania não estaria em xeque, bem como o direito administrativo também não será extinto, estes sofrerão adaptações ligadas às normativas da globalização.

Para muitos, e principalmente, os seguidores da Escola Austríaca de Economia $^{14}$, a tecnologia é necessariamente libertadora, pois a Blockchain e as criptomoedas são tidas como instrumentos emancipatórios da sociedade diante de um Estado opressor e ineficiente. Não é à toa que orientações políticas próximas ao anarquismo defendem a ideia de que essas tecnologias são vistas como uma alternativa eficiente para substituir as funções que hoje são assumidas pelos Estados. Por outro lado, essa mesma tecnologia tem um potencial para ser um instrumento de dominação, sendo que a sua escolha não é puramente livre, uma vez que no atual contexto econômico globalizado as escolhas de consumo acabam sendo feitas pelos grandes conglomerados.

\footnotetext{
${ }^{14}$ Mesmo que não seja o foco do presente artigo, mostra-se necessário pontuar brevemente que a Escola Austríaca estabeleceu uma linha de pensamento voltado aos estudos econômicos, ditos neoliberais. Friedrich Hayek é considerando como o principal autor dessa vertente do neoliberalismo, sendo a principal referência bibliográfica o "Caminho da Servidão", publicado pela primeira vez em 1944.
} 
Diante de uma série de influências políticas e econômicas, o debate sobre a regulação tecnológica não é meramente técnico, mas sim uma reflexão sobre o poder, em várias das suas manifestações. Afinal, partindo-se do ponto que sociedades organizadas necessitam de alguma forma de regulação, a tecnologia não pode ser considerada como uma forma paralela à regulação, mas uma forma própria de regulação. Destaque-se que a depender da escolha da tecnologia e sua respectiva utilização, a alocação de recursos e direitos podem ser drasticamente alterados (FRAZÃO, 2017). O conflito de interesses quanto aos instrumentos de regulação não é uma situação tão nova, basta referenciar as colisões entre o direito à privacidade e o interesse público nos casos acesso aos dados do aplicativo do Whatsapp no Brasil e da quebra de sigilo da Apple em investigações contra ameaças terroristas nos Estados Unidos $^{15}$. Nesse contexto, o principal questionamento porto é no sentido de saber “quem" decide qual tecnologia será utilizada, como tal decisão é tomada e a quais interesses, valores ou objetivos ela se prestará.

Ocorre que uma das características da quarta revolução industrial contribui negativamente para o debate sobre a necessidade de regulação, uma vez que a amplitude e extrema velocidade das tecnologias criam situações sem um respaldo jurídico ${ }^{16}$, como é o caso das criptomoedas. Objetivamente, não basta que uma tecnologia seja pensada apenas com o intuito de satisfazer consumidores e fomentar o crescimento econômico, ainda que isso seja relativo, mas também a sobre um viés cidadão e de crescimento econômico sustentável e inclusivo.

Em âmbito nacional, o chefe-adjunto do departamento de supervisão bancária do Banco Central do Brasil, Fábio Lacerda Carneiro chegou a declarar em um evento promovido pelo Instituto dos Advogados de São Paulo no ano de 2017 que a Bitcoin "nasceu para não ser regulada", bem como "a pouca relevância sistêmica em torno do bitcoin autoriza o regulador a seguir apenas monitorando o mercado e orientando a sociedade” (PIMENTA, 2017). Bem verdade que em sentido mais amplo há a regulação

\footnotetext{
${ }^{15}$ Integrantes do grupo Estado Islâmico utilizaram os aplicativos do WhatsApp e Twitter para propagar ideias terroristas em 2015: Disponível em: <http://g1.globo.com/tecnologia/noticia/2015/11/estadoislamico-usa-de-whatsapp-twitter-para-promover-terrorismo-viral.html.> Acesso em 07 jan. 2020.

16 "Enquanto os governantes e a sociedade civil não sabem o que fazer, os agentes empresariais muitas vezes se aproveitam da inação, do excesso de otimismo das pessoas e das zonas de penumbra da regulação para avançar em diversas searas, inclusive por meio de modelos de negócio supostamente imunes a qualquer regulação jurídica. Esse tipo de empreendedorismo - visto por uns como criatividade, por outros como verdadeira fraude - coloca-nos diante de novos questionamentos, que desafiam as posturas simplistas de que novos negócios ou são "mais do mesmo" ou são totalmente diferentes dos serviços tradicionais.” (FRAZÃO, 2017)
} 
econômica de moeda prevista na Constituição de 1988, uma vez que a emissão do Real é uma competência da União ${ }^{17}$, sendo uma atribuição exclusiva do Banco Central do Brasil $^{18}$. Objetivamente a Carta Constitucional confere ao ente máximo do Estado brasileiro o controle sobre a emissão e movimentação financeira na fiat corrente. Ademais, saliente-se que o inciso VII do mesmo artigo estabelece que compete à União a administração das reservas cambiais, bem como a fiscalização das operações de natureza financeira, de crédito, câmbio, capitalização, seguro e previdência privada. $\mathrm{Ou}$ seja, firma a ideia de que, independentemente do tipo de operação financeira, esta deveria ser fiscalizada.

Ocorre que o posicionamento externalizado pelo representante do ente estatal sofreu alterações em razão do exponencial crescimento do uso das criptomoedas. Assim, a Receita Federal, atenta ao crescimento das movimentações financeiras através de criptoativos, editou a Instrução Normativa RFB n. 1888, a qual classifica, ainda que exclusivamente para fins de arrecadação de tributos, os criptoativos como uma “representação digital de valor, cujo preço pode ser expresso na moeda soberana local (real, dólar, euro etc.) que pode ser utilizada como forma de investimento, transferência, bem como meio de pagamento de serviços, mas não constitui moeda de curso legal"19. Apesar de reconhecer expressamente que não se trata de uma moeda de monopólio estatal, afirmou sua relevância comercial para fins tributáveis como um esboço de fiscalização até então inexistente.

Ainda que anterior e sem uma definição, uma vez que aguarda parecer do Relator na Comissão Especial, há o Projeto de Lei n. 2.303/2015 ${ }^{20}$ de autoria do

\footnotetext{
17 “Art. 21. Compete à União: (...) VII - emitir moeda; VIII - administrar as reservas cambiais do País e fiscalizar as operações de natureza financeira, especialmente as de crédito, câmbio e capitalização, bem como as de seguros e de previdência privada;". Disponível em <http://www.planalto.gov.br/ccivil 03/constituicao/constituicao.htm> Acesso 16 out. 2019.

18 "Art. 164. A competência da União para emitir moeda será exercida exclusivamente pelo banco central". Disponível em 〈http://www.planalto.gov.br/ccivil 03/constituicao/constituicao.htm> Acesso 16 out. 2019.

19 “Art. $5^{\circ}$ Para fins do disposto nesta Instrução Normativa, considera-se: I - criptoativo: a representação digital de valor denominada em sua própria unidade de conta, cujo preço pode ser expresso em moeda soberana local ou estrangeira, transacionado eletronicamente com a utilização de criptografia e de tecnologias de registros distribuídos, que pode ser utilizado como forma de investimento, instrumento de transferência de valores ou acesso a serviços, e que não constitui moeda de curso legal;" BRASIL, Receita Federal. Disponível em $<$ http://normas.receita.fazenda.gov.br/sijut2consulta/link.action?visao=anotado\&idAto=100592 $>$

Acesso 11 nov. 19.

${ }^{20}$ Acompanhamento do trâmite legislativo disponível em: $\langle$ https://www.camara.leg.br/proposicoesWeb/fichadetramitacao?idProposicao=1555470〉 Acesso em 10 jan. 2020.
} 
Deputado Federal Áureo Ribeiro ${ }^{21}$, o qual entre outras diretrizes, visa disciplinar os pagamentos nos ditames do Conselho Monetário Nacional, o qual também passaria a regular os pagamentos baseados em moedas virtuais e programas de milhagens aéreas.

\section{REGULAÇÃO COMO UMA FORMA DE INTERVENÇÃO ESTATAL NA ECONOMIA}

${ }^{21} \mathrm{O}$ autor do Projeto de Lei a presentou a seguinte justificativa para a regulamentação legal: “As chamadas "moedas virtuais" ganham cada vez mais destaque nas operações financeiras atuais. Apesar de não haver ainda uma regulamentação nem nacional e nem internacional sobre a matéria, há uma preocupação crescente com os efeitos das transações realizadas por meios destes instrumentos. $\mathrm{O}$ assunto mereceu um relatório especial do Banco Central Europeu (BCE) em outubro de 2012, que foi atualizado em fevereiro de 2015. Apesar de concluir pela desnecessidade da introdução imediata de uma regulação mais ativa sobre as moedas virtuais, tal relatório aponta um conjunto de riscos que devem ser devidamente monitorados. Colocaremos a seguir um quadro com cada uma das principais conclusões do relatório e um comentário. Sobressai-se nesta análise das moedas virtuais o que é considerado o maior caso de "sucesso" que é o Bitcoin. Conforme o relatório do ECB de 2012: "Desenhado e implementado pelo programador japonês Satoshi Nakamoto em 2009, o esquema é baseado em uma rede peer-to peer similar ao Bit Torrent, o famoso protocolo de compartilhamento de arquivos como filmes, jogos e música na internet. O Bitcoin opera globalmente e pode ser usado como moeda para todos os tipos de transação (para ambos bens, e serviços virtuais e reais), competindo portanto com as moedas oficiais como o euro e o dólar.... embora o Bitcoin seja um esquema de moeda virtual, possui algumas inovações que a tornam mais similar à moeda convencional" (tradução livre). O mais importante para nós, no entanto, são os riscos potenciais apontados no relatório para o Bitcoin: "De tempos em tempos, o Bitcoin é cercado por controvérsias. Algumas vezes ressalta-se o seu potencial para se tornar uma alternativa monetária ao tráfico de drogas e lavagem de dinheiro, como resultado do elevado grau de anonimato. Em outras ocasiões, os usuários têm reclamado ter sofrido um roubo substancial de Bitcoins através de um "cavalo de troia" que ganhou acesso ao seu computador. A Fundação Fronteira Eletrônica, que é uma organização que busca defender a liberdade no mundo digital, decidiu não mais aceitar doações em Bitcoins. Entre as razões dadas, eles consideraram "que a Bitcoin gera preocupações legais ainda não testadas relacionadas às lei de ativos financeiros, com o "Stamp Payment Act" (legislação que proíbe qualquer pagamento abaixo em moeda, nota ou cheque abaixo de \$1), de evasão de tributos, de proteção do consumidor e lavagem de dinheiro, entre outros" (tradução livre)" O Relatório do BCE também possui um box específico (box 1) para os programas de milhagem. O efeito de tais programas, enquanto uma "moeda paralela", não pode ser subestimado. O Relatório cita matéria do "The Economist" de 2005 que mostra que tais programas, já naquela época, atingiam valores significativos, inclusive ultrapassando a quantidade de dólares em circulação. O Relatório inclui os programas de milhagem como um tipo específico de "moeda virtual". Em certa medida acreditamos que tanto o Banco Central como o Conselho de Controle de Atividades Financeiras (Coaf) e os órgãos do consumidor já tem competência para fiscalizar e regular moedas virtuais. No entanto, entendemos que as legislações que conferem tais atribuições podem ser mais transparentes em relação a tais atribuições, o que evita desnecessários questionamentos judiciais. Sendo assim, endereçamos no projeto de lei proposto três questões relacionadas às moedas virtuais, uma em cada artigo: i) regulação prudencial pelo Banco Central, ii) lavagem de dinheiro e outras atividades ilegais e iii) defesa do consumidor. Deixamos claro no art. 1o que os "arranjos de pagamento" citados no inciso I do art. 9o da Lei 12.865, de 09 de outubro de 2013 inclui "aqueles baseados em moedas virtuais e programas de milhagens aéreas". Ademais, deixamos claro no art. 2o que as operações que envolvem moedas virtuais estão incluídas na fiscalização do COAF: Por fim, não deixamos margem a dúvida de que a legislação de defesa do consumidor se aplica ao mundo das moedas virtuais no art. 3o". ibid. 
Diante de um cenário ainda carente de maiores definições legais e com uma considerável parcela de desconhecimento sobre o tema, subsiste importante espaço para uma discussão sobre a regulação jurídica, não apenas no âmbito doméstico, a qual seria inócua em uma economia globalizada, mas principalmente no âmbito internacional. É certo que, para isso, será necessária uma completa revisitação de categorias jurídicas, como a propriedade intelectual. Também não se discute que, em muitos casos, novas categorias deverão ser criadas, assim como novas alternativas de regulação deverão ser implementadas (FRAZÃO, 2017).

Entretanto, a prioridade é uma reflexão crítica a respeito das atribuições da tecnologia, sobre quem deve decidir os conflitos a ela inerentes, bem como de que maneira serão solucionados, e, por fim, para qual finalidades ela se prestará. Sem essas premissas, a solução de vários dos problemas será precipitada, casuística e facilmente suscetível aos interesses políticos, "mascarados" de interesses econômicos.

Nesse contexto, inevitável é referenciar as alterações apresentadas na Lei de Introdução ao Direito Brasileiro, as quais preveem que a fundamentação jurídica possa e deva manter os desdobramentos principiológicos e finalísticos (FRAZÃO, 2019) ${ }^{22}$. Desta forma, cria-se um ambiente propício para a utilização de "metodologias econômicas", as quais caracterizam-se pelas fortes preocupações quantitativas. Ou seja, propõem-se mensurar de forma objetiva as consequências de determinadas alternativas e, consequentemente, oferecer uma segura margem para a escolha. Por outro lado, ainda dentro dos preceitos da LINDB, o diálogo entre direito e economia reclama maiores percalços, uma vez que, segundo Ana Frazão, não de pode falar em “consenquencialismo" ou um exercício de previsibilidade sobre pré-compreensões que influenciam direta ou indiretamente o alcance, o rigor e até a confiabilidade das metodologias utilizadas para aplicar o direito. Em outros termos, os exemplos históricos demonstram que quando a economia norteia as discussões, as estimativas e suas consequências necessárias são consideravelmente imprecisas, o que as tornam discutíveis. Por tal razão é que a confiabilidade nos modelos tradicionais, cujo modelo é atribuído a Keynes e Minsky, é limitada e precária.

Em sentido oposto, adotando premissas de racionalidade e estabilidade dos mercados, seria, ao menos em tese, mais viável não somente a previsibilidade dos

\footnotetext{
${ }^{22}$ Disponível em: < https://www.jota.info/opiniao-e-analise/colunas/constituicao-empresa-e-mercado/aimportancia-da-analise-de-consequencias-para-a-regulacao-juridica-29052019 Acesso em 11 jan. 2020.
} 
acontecimentos, mas também o cálculo de riscos. Tal estudo preliminar é relevante no sentido de que este se mostra apto para ressaltar que muitas das metodologias de previsibilidade adotam a última postura. Ou seja, adotam premissas muito questionáveis, como conceber que os agentes de mercado são racionais e independentes e que os mercados são livres, justos, estáveis e refletem corretamente valor e risco (FRAZÃO, 2019). Outro ponto de relevante destaque diz respeito a utilização crescente da econometria nas estimativas feitas, sem a necessária reflexão sobre a confiabilidade das premissas que fundamentarão as análises pelo direito. Consequentemente, como as regras da economia não são universais (RODRIK, 2015), são instáveis e sujeitas a inúmeras peculiaridades, os resultados, positivos ou não, podem apoiar-se em quaisquer das categorias de argumentos. Nessa mesma linha, Ana Frazão (2009) faz referência a uma relevante afirmação de Jerry Muller (apud FRAZÃO, 2019), no sentido de que "nem tudo que é importante é mensurável e nem tudo que é mensurável é importante". Ou seja, o imponderável predomina na análise econômica.

A conclusão obvia é de que mensurar consequências é uma tarefa árdua e que, muitas vezes, não apresenta resultados fiéis. Desta feita, resta claro o exemplo de que a substituição de metodologias jurídicas por metodologias econômicas será capaz de solucionar, de forma objetiva e segura, assuntos humanos complexos. Tal conclusão é ainda mais latente no mundo globalizado e digital, no qual se utilizam algoritmos para mensurações e previsões, sem uma complementar evidência empírica do imponderável. Mais: a falta de questionamento sobre as premissas e sobre as características econômicas leva, nas palavras de Ana Frazão (2019), a um "consequenciachismo"23. Portanto, se a análise das consequências e riscos tem como finalidade proporcionar decisões eficientes, garantindo a segurança jurídica, o “consequenciachismo” levará a um resultando oposto, pois substituirá a subjetividade das discussões jurídicas pela subjetividade de métodos econômicos discutíveis.

\section{CONCLUSÃO.}

\footnotetext{
23 expressão debochada que vem sendo utilizada para a estimativa de consequências feita sem rigor científico, muitas vezes com base ou no que se chama de "senso comum" ou em modelos econômicos excessivamente abstratos e idealizados, sem correspondência consistente com os fatos concretos (FRAZÃO, 2019)
} 
Indiscutivelmente a criação e a constante utilização das criptomoedas sintetizam vários aspectos da revolução digital, pois propiciam uma economia mundial, rápida e sem intermediários. Além disso, defende-se que o uso das criptomoedas seria uma forma eficiente de combater a tirania, principalmente monetária, exercida pelo Estado (ULRICH, 2014). Afinal, é importante relembrar que o Bitcoin entrou no mercado como uma resposta à crise monetária do final de 2008, quando se intensificaram as discussões sobre o papel interventor do Estado na economia.

Deixar os agentes econômicos mais livres para poder realizar tratativas nacionais e internacionais sem o aval de um Estado soberano foi e ainda é uma grande mudança de paradigma, uma vez que acaba por quebrar o monopólio do dinheiro e, consequentemente, com perda considerável de poder político. Ocorre que a disseminação da ideia de acabar com o monopólio do dinheiro não é recente e nem exclusiva de uma única escola econômica. Apenas a título de curiosidade, Milton Friedman, principal nome da Escola de Chicago, em entrevista concedida durante a premiação do Nobel em 1999, já previu que uma moeda digital surgiria para reduzir o papel do governo ${ }^{24}$.

Apesar de um dos principais nomes da economia ter conseguido realizar um exercício de previsibilidade correto, as estimativas e ponderações econômicas não possuem a mesma credibilidade e eficiência, pois acabam por se tornar "consequenciachismos" (FRAZÃO, 2019). Some-se ao fato de que as principais limitações do âmbito legal e, consequentemente, regulatório, são reforçadas em razão de ainda não chegaram a um denominador comum no tocante aos conceitos tecnológicos. Tal empecilho legal está intrinsicamente ligado ao pronunciamento do Estado, uma vez que a ampliação do uso das criptomoedas atesta a perda de poder.

Assim, a preponderância de dificuldades sobre modalidade, competência e definições conceituais não permite conclusões imediatas sobre a regulação estatal das

\footnotetext{
24 "I think the Internet is going to be one of the major forces for reducing the role of the government. The one thing that's still missing but that will soon be developed is a reliable e-Cash - a method whereby on the internet you can transfer funds from A to B, without A knowing A or B knowing A, the way in which I can take a $\$ 20$ bill and hand it over to you and there is no record where it came from. You may get that without knowing who I am, that kind of thing that will develop on the internet and that would made it even easier for people to use internet. Of course it has it's negative side, it means that gangsters, the people who are engaging in illegal transactions will also have an easier way to carry on their business, but I think that the tendency that make it harder to collect taxes will be a very important positive effect of the internet." FRIEDMAN, Milton. Milton Friedman predicts the rise of Bitcoin in 1999. Coi Republic. Disponível em < https://www.youtube.com/watch?v=6MnQJFEVY7s > Acesso em 11 nov. 2019.
} 
criptomoedas. Nesse sentido, Renato de Mello Jorge Silveira define bem o atual situação das criptomoedas: "Talvez o grande problema das criptomoedas seja o fato de que elas nasceram para se pautar como mercado paralelo de pagamentos e, inusitadamente, passaram a ser vistas como um grande mercado de ativos financeiros" (2018, p. 143). Consequentemente, ao se estabelecer como um grande mercado de ativos, as atenções voltam-se cada vez mais para ele, mesmo que não se tenha, até o presente momento, uma alternativa viável de controle.

Pontue-se, também, que a aparente falta de alternativas de regulação da moeda digital não pode ser transferida por uma limitação de fontes energéticas. Ao limitar, ou ainda, regular o acesso à eletricidade e, consequentemente, à internet através de uma maior tributação, o Estado internet não prejudicará apenas o mercado de criptoativos, mas sim toda a economia ${ }^{25}$. Vale lembrar que o dinheiro tradicionalmente impresso não é mais o meio de pagamento mais utilizado e os serviços de internet banking já representam maioria no mercado.

Portanto, conclui-se que os reflexos da quarta revolução industrial são ilimitados e de uma amplitude jamais vista ${ }^{26}$, sendo necessária uma reformulação no que diz respeito ao grau de intervenção estatal nas questões econômicas. Proibir o uso, criminalizar ou restringir acesso ao mundo digital mostra-se precipitado, materializando um pensamento limitado e em face de tecnologias que ainda não foram devidamente valoradas em sua notória complexidade.

\section{REFERÊNCIAS BIBLIOGRÁFICAS.}

BAUMANN, Zigmunt. Modernidade Líquida. Tradução de Plínio Dentzien. Rio de Janeiro: Zahar, 2003.

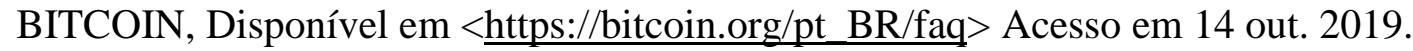

\footnotetext{
25 "Aliás, considerando que governo nenhum até hoje logrou conter nenhuma rede BitTorrent, não me parece plausível esperar que conseguiriam causar danos irreparáveis ao maior projeto de computação distribuída do mundo (sim, Bitcoin já ultrapassou o projeto SETI, Search for Extra Terrestrial Intelligence)." ULRICH, Fernando. Bitcoin: objeções e mais objeções (Parte 3). < https://www.mises.org.br/article/1585/bitcoin-objecoes-e-mais-objecoes-parte-3>

26 "Precisamos de uma visão compartilhada abrangente e global sobre como a tecnologia tem mudado nossas vidas e mudará a das gerações futuras, e sobre como ela está remodelando o contexto econômico, social, cultural e humano em que vivemos." (SCHWAB, p.12, 2016).
} 
BRASIL, Constituição da República (1988). Disponível em < http://www.planalto.gov.br/ccivil_03/constituicao/constituicao.htm> Acesso em 12 mov. 2019.

BRASIL, Código Penal (1940). Disponível em < http://www.planalto.gov.br/ccivil_03/decreto-lei/del2848compilado.htm> Acesso em 12 mov. 2019.

BRASIL, Receita Federal. Instrução Normativa RFB n. 1888, de 03 de maio de $2019 . \quad$ Disponível em <http://normas.receita.fazenda.gov.br/sijut2consulta/link.action?visao=anotado\&idAt $\underline{\mathrm{o}=100592}>$ Acesso 11 nov. 19.

BRASIL, Câmara dos Deputados. Projeto de Lei n. 2.303/2015. Disponível em <hhttps://www.camara.leg.br/proposicoesWeb/fichadetramitacao?idProposicao=1555 $\underline{470>}$ Acesso 10 jan. 2020.

ESTELLITA, Heloisa. Bitcoin e lavagem de dinheiro: uma aproximação. Penal em foco. Portal Jota. Disponível em https://www.jota.info/paywall?redirect to=//www.jota.info/opiniao-eanalise/colunas/penal-em- foco/bitcoin-e-lavagem-de-dinheiro-uma-aproximacao$\underline{07102019>}$ Acesso em 12 nov. 19.

FERREIRA, Natasha Alves. Incertezas jurídicas e econômicas da bitcoin como moeda. In: CONPEDI/UFPB. (Org.). Direito e economia II. $1^{\mathrm{a} e d}$. Florianópolis: CONPEDI, 2014.2 Disponível em: < http://www.publicadireito.com.br/artigos/?cod=1ecccc0718eb6582> Acesso em 22 de out. 2019.

FIORILlO, Celso Antônio Pacheco; CONTE, Christiany Pegorari. Crimes no meio ambiente digital e a sociedade da informação. 2 ed. São Paulo: Saraiva, 2016.

FRAZÃO. Ana. Premissas para a reflexão sobre a regulação da tecnologia. Para que deve servir a regulação da tecnologia? Disponível em< https://www.jota.info/opiniao-e-analise/colunas/constituicao-empresa-emercado/premissas-para-a-reflexao-sobre-a-regulacao-da-tecnologia-16112017 > Acesso em 07 jan. 2020.

FRAZÃO. Ana. A importância da análise de consequências para a regulação jurídica. Perspectivas e riscos do consencialismo e do 'consequenciachismo' Disponível em https://www.jota.info/opiniao-e-analise/colunas/constituicao-empresae-mercado/a-importancia-da-analise-de-consequencias-para-a-regulacao-juridica$\underline{29052019}>$ Acesso em 07 jan. 2020.

FRIEDMAN, Milton. Milton Friedman predicts the rise of Bitcoin in 1999. Coi Republic. Disponível em < https://www.youtube.com/watch?v=6MnQJFEVY7s> Acesso em 11 nov. 2019.

GUERRA, Gustavo Rabay; MARCOS, Henrique Jerônimo Bezerra. LEGAL REMARKS ON THE OVERARCHING COMPLEXITIES OF CRYPTO ANTI- 
MONEY LAUNDERING REGULATION. Revista Juridica, [S.1.], v. 4, n. 57, p. 83 - 115, out. 2019. ISSN 2316-753X. Disponível em: <http://revista.unicuritiba.edu.br/index.php/RevJur/article/view/3757/371372117>. Acesso em: 25 abr. 2020. doi:http://dx.doi.org/10.21902/revistajur.2316753X.v4i57.3757.

HAYEK, Friedrich A. Desestatização do Dinheiro. São Paulo: Instituto Ludwig von Mises. Brasil, 2011. p.30/31.

HAYEK, Friedrich A. Monetary theory and the trade cycle, 1 ed. New York: Sentry press, 1933. p.140.

HAYEK, Friedrich A. Direito, Legislação E Liberdade. São Paulo: Visão. 1985. Vol. III A Ordem Política de um Povo Livre. p.61.

LOPES, J.C. \& ROSSETTI, J.P. Economia Monetária. 9.ed. São Paulo: Editora Atlas, 2009.

MISES, Ludwig Von. A Teoria Austríaca dos Ciclos Econômicos. Instituto Ludwig Von Mises, 27, ago. 2008

MISES, Ludwig Von. A Teoria Austríaca dos Ciclos Econômicos. Instituto Ludwig Von Mises, 27, ago. 2008. Disponível em: < http://www.mises.org.br/Article.aspx?id=149>. Acesso em 23 jan.2014.

MULLER, Jerry. The tyranny of metrics. New Jersey: Princeton University Press, 2018.

PIMENTA, Guilherme. Bitcoin: como regular o que nasceu para não ser regulado? Disponível em: <https://www.jota.info/justica/bitcoin-como-regular-o-que-nasceupara-nao-ser-regulado-31082017 Acesso em 08 jan. 2020.

RODRIK, Dani. Economics Rules. The rights and wrongs of the dismal science. New York: WW. Norton \& Company, 2015.

SCHWAB, Klaus. A quarta revolução industrial. Tradução Daniel Moreira Miranda - São Paulo: Edipro, 2016.

SILVEIRA, Renato de Mello Jorge. Bitcoin e suas fronteiras penais: em busca do marco penal das criptomoedas. $2^{\mathrm{a}}$ reimpressão. Belo Horizonte: D’Plácido, 2018.

STELlA, Júlio Cesar. Moedas Virtuais no Brasil: como enquadrar as criptomoedas. Revista da PGBC - Volume II, número 2, Dezembro de 2017.

SUNDFELD, Carlos Ari. O direito administrativo sobreviverá à globalização?, In Direito administrativo para céticos. $2^{\mathrm{a}}$ ed. revisada e ampliada. São Paulo: Malheiros, 2014. 
ULRICH, Fernando. Bitcoin: o Nascimento do dinheiro... (parte 1). O Ponto Base, 19, abr. 2013. Disponível em: https://www.mises.org.br/article/1579/bitcoin-onascimento-do-dinheiro-parte-1 Acesso em 11 nov. 2019.

ULRICH, Fernando. Bitcoin: melhor que ouro e papel-moeda (parte 2). Disponível em < https://www.mises.org.br/Article.aspx?id=1581> Acesso em 12 nov. 2019.

ULRICH, Fernando. Bitcoin: objeções e mais objeções (Parte 3). < https://www.mises.org.br/article/1585/bitcoin-objecoes-e-mais-objecoes-parte-3 2018. P. 133 